\title{
ODELOUCA DAM CONSTRUCTION: NUMERICAL ANALYSIS
}

\author{
A. Brito ${ }^{1}$, J. R. Maranha ${ }^{1}$, L. Caldeira ${ }^{1}$ \\ ${ }^{1}$ Geotechnical Department, LNEC, Civil Engineering National Laboratory, Portugal (andrea- \\ brito.lnec@gmail.com)
}

\begin{abstract}
Odelouca dam is an embankment dam, with $76 \mathrm{~m}$ height, recently constructed in the south of Portugal. It is zoned with a core consisting of colluvial and residual schist soil and with soil-rockfill mixtures making up the shells (weathered schist with a significant fraction of coarse sized particles).

This paper presents a numerical analysis of Odelouca Dam`s construction. The material constants of the soil model used are determined from a comprehensive testing programme carried out in the Civil Engineering National Laboratory (LNEC) during the dam construction for the hydraulic and mechanical characterization of the materials used. Computational results are then compared between to the ones obtained from the dam monitoring system during the construction stage.
\end{abstract}

Keywords: Embankments dams, Soil-rockfill mixtures, Soil constitutive models.

\section{INTRODUCTION}

The use, due to economical and environmental reasons, of non traditional materials, such as soil-rockfill mixtures, in the construction of earthworks, brings new challenges to dam engineering. Usually, this kind of material results from the disaggregation by mechanical means of rock masses (without explosives), and it can include some large sized particles (about 0.5 $\mathrm{m}$ or larger). The behaviour of these materials depends on the relative fractions of their constituents, becoming closer to a soil, when the fine fraction is prevalent with the coarser material scattered in it, or closer to a rockfill, when the coarser particles are in contact with each other with the fines occupying the spaces between them.

In order to understand the behaviour of this material, a testing and a numerical modelling program were implemented at the Civil Engineering National Laboratory $(L N E C)$ in Portugal. The materials used in the studies came from the shoulders and core of Odelouca Dam. This paper presents numerical analyses of laboratory tests and Odelouca Dam`s construction. The material constants of the soil model used are determined from the testing programme for the hydraulic and mechanical characterization of the materials used. Computational results are then compared between to the ones obtained from the dam monitoring system during the construction stage. 


\section{GENERAL CHARACTERISTICS OF ODELOUCA DAM}

Odelouca dam is a zoned embankment dam, with $76 \mathrm{~m}$ of height, located in Algarve, in the south of Portugal. The crest of dam, $11 \mathrm{~m}$ wide, is approximately $415 \mathrm{~m}$ long. Figure 1 shows the dam cross-section.

The reservoir created by Odelouca dam encompasses a $7.8 \mathrm{~km}^{2}$ area and has a $157 \mathrm{hm}^{3}$ capacity at the maximum water level. Most of this volume is intended for water supply with a small part used to irrigate the downstream fields.

The embankment materials include clayey soil, in the core, and weathered schist and greywacke (soil-rockfill mixture), with a significant fraction of large sized particles, in the shells. The use of materials, extracted mainly from the reservoir area, minimize the negative environmental impacts. The upstream slope incorporates the cofferdam creating a $14 \mathrm{~m}$ wide berm.

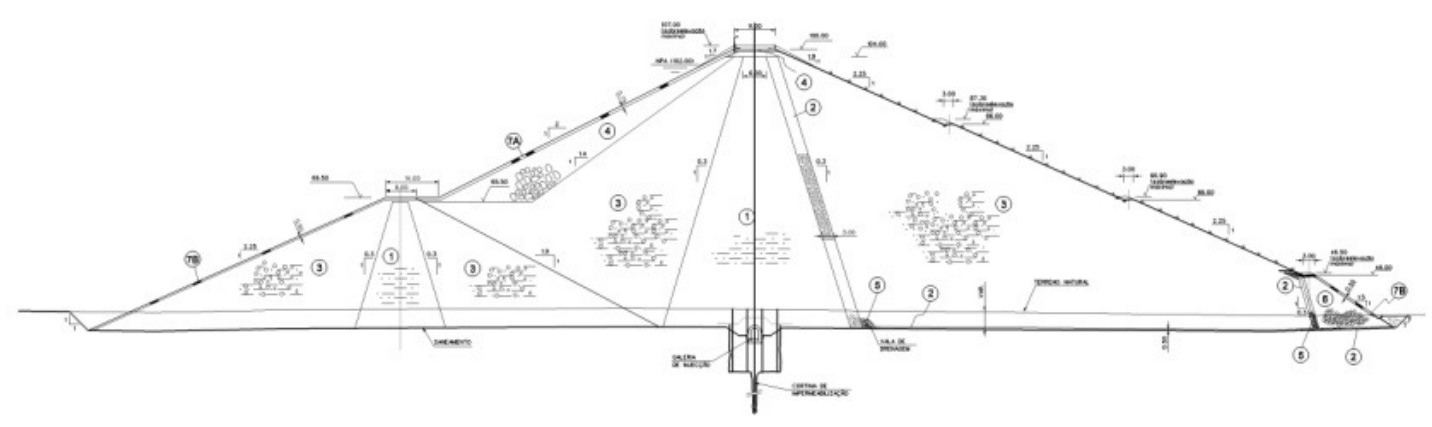

Figure 1 - Odelouca dam cross-section.

\section{MODELING LABORATORY TESTS}

During the dam construction and afterwards, a comprehensive testing programme was carried out at $L N E C$ for the hydraulic and mechanical characterization of the materials used. One of first steps in the research programme consisted in finding a soil model able to adequately reproduce the tests performed in the clay material used in the core and in the soilrockfill material used in the shoulders.

In this analysis the explicit finite difference program FLAC was used. This is a twodimensional program for geotechnical applications that allows the implementation of constitutive laws by the user.

\subsection{Elastoplastic Modified Cam Clay Model}

Due to its relative simplicity, the Modified Cam Clay Model (MCCM) [1] was first applied in modelling the tests performed on Odelouca dam's materials.

The MCCM is an elastoplastic model with hardening that incorporates, in a very simplified way, several fundamental aspects of soil behaviour.

The yield function used by the model, describes an ellipse in $\left(p^{\prime}, q\right)$ space which is given by the following equation: 


$$
f(\sigma)=f\left(p^{\prime}, q\right)=\left(\frac{q}{M}\right)^{2}+p^{\prime}\left(p^{\prime}-p_{c}\right)=0
$$

where $M$ is the slope of the critical state line and $p_{c}$ is the isotropic pre-consolidation stress.

This model assumes an associated flow rule making the plastic strain increments orthogonal to the yield surface in stress space.

Another feature of this model is that the hardening law is determined solely by the plastic volumetric strain increment.

The MCCM is already included in the program FLAC and was used to reproduce a set of three tests of the core material and a set of three tests of the shoulder's material used in Odelouca's dam construction. They were undrained triaxial compression tests consolidated isotropically to three values of effective mean stress: 200, 400 and $800 \mathrm{kPa}$.

Figure 2 and Figure 3 present, respectively, for the core and shoulders materials, the comparison between the results from the triaxial tests and those computed with the MCCM. The figures show the deviatoric stress invariant, $q$, versus the axial strain and the effective stress paths.

The comparison of the results for the core material shows that the model's response shows a stiffness similar to the measured for strains of up to $2 \%$ (for all 3 samples) and becomes quite softer for larger strains. Furthermore, it is incapable of reproducing the inversion in direction observed in the effective stress paths.
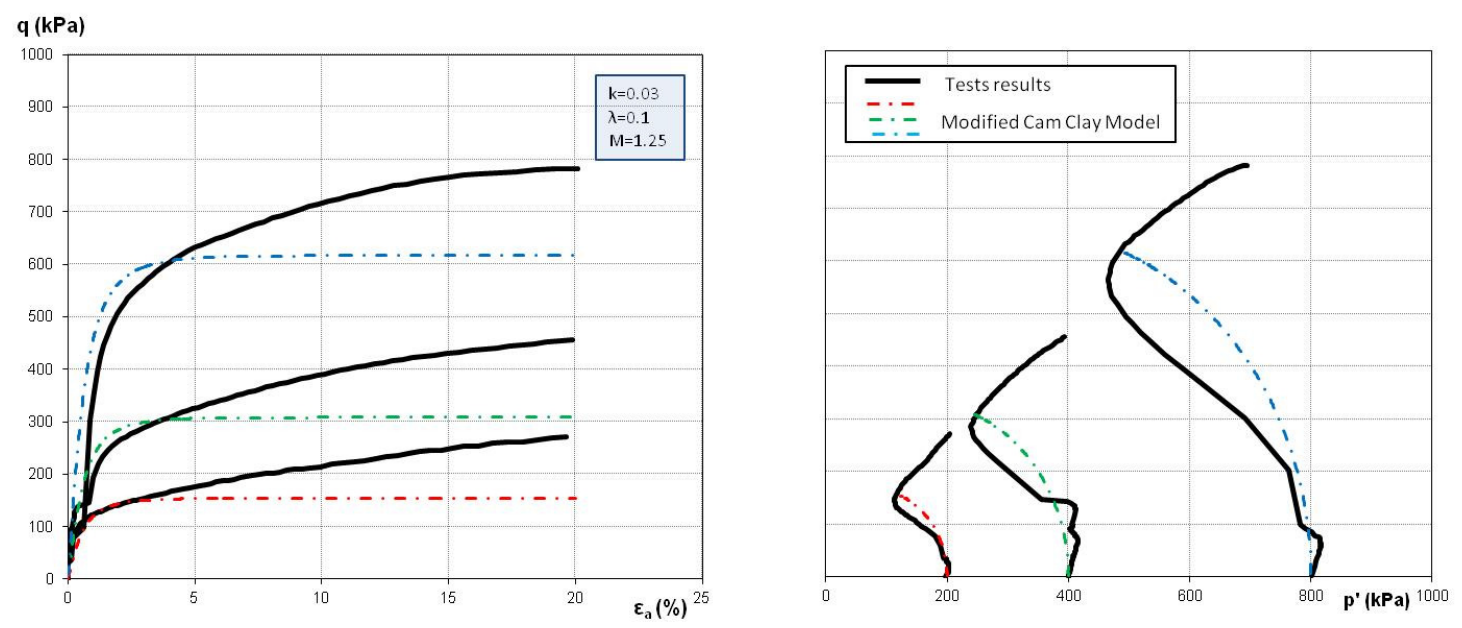

Figure 2 - Comparison between the results of the triaxial tests and the Modified Cam Clay Model for the dam's core material.

In the case of the shoulders material consolidated at $800 \mathrm{kPa}$, the MCCM computed response is a bit stiffer than the measured for axial strains below $1 \%$, becoming softer for higher strain levels. The MCCM computed response for the shoulders material sample consolidated at $400 \mathrm{kPa}$, shows the same stiffness as the measured for axial strains below $1 \%$, becoming softer for higher strain levels. The MCCM computed response for the sample consolidated at $200 \mathrm{kPa}$ is always softer than the observed.

The Cam Clay model is a model that exhibits a sharp transition in rigidity when going from elastic to elastoplastic behaviour. This proved to be a limitation of the model for the tested materials since they have a more gradual transition. Also, the materials tested presented an effective stress path with an inversion in direction (as can be seen in Figure 2 and Figure 3) which the MCCM was as well unable to reproduce. 

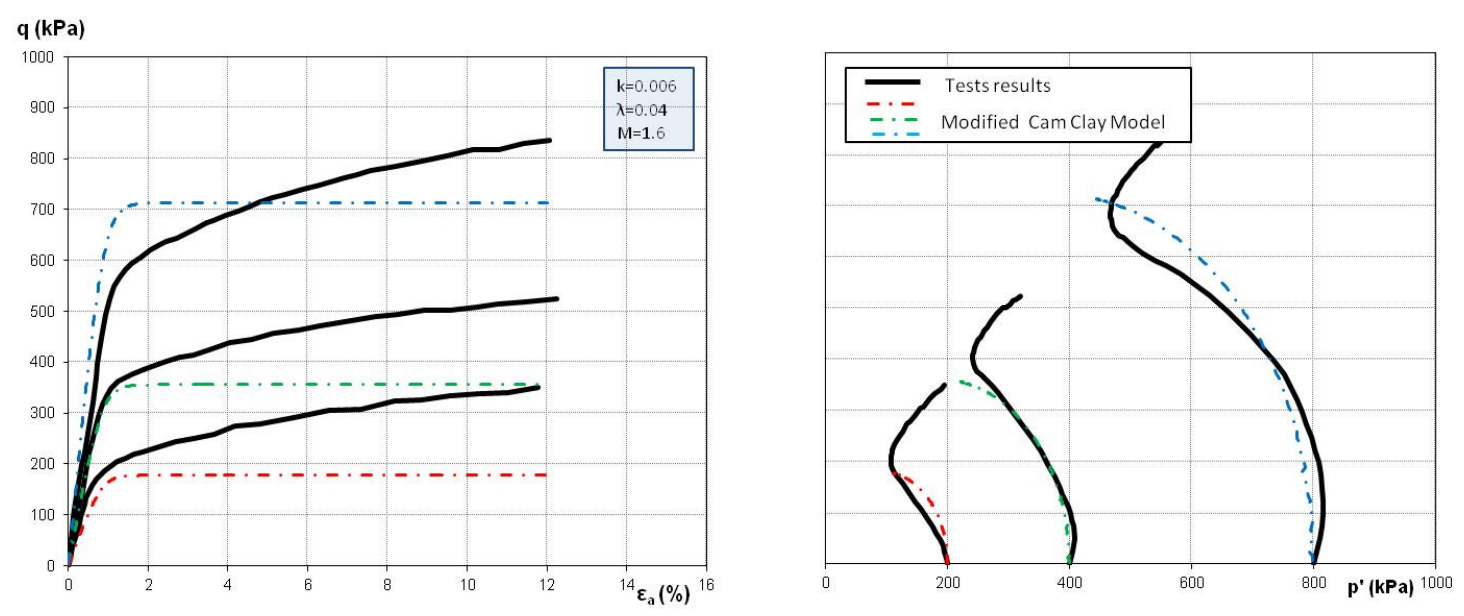

Figure 3 - Comparison between the results of the triaxial tests and the Modified Cam Clay Model for the dam's shoulders material.

Thus, the next step in the mathematical modelling was the search for a model capable of describing a more gradual and controlled transition between the elastic and elastoplastic behaviour, thereby enabling an improvement in the description of the observed behaviour. A family of models having this feature are the Subloading Surface Models.

\subsection{Subloading Surface Model}

The Subloading Surface Model, SSM, ( [2] [3] [4]) is an unconventional elastoplastic model that extends elastoplasticity theory in such a way that the interior of the yield surface is not a purely elastic domain. Instead a plastic strain rate is induced by the rate of stress inside the yield surface. Thus, the conventional yield surface is, in this model, renamed the normal yield surface, since its interior is not a purely elastic domain.

In this model the evolutionary process of the normal yield surface occurs by isotropic hardening and the surface containing the stress point, named Subloading Surface, is homothetic from the normal yield surface, requiring only an internal variable scale $(R-$ normal yield ratio) defining its scale, as can be seen in Figure 4. The null stress state corresponds to $R=0$, the sub-yield state to $0<R<1$ and the normal yield state to $R=1$.

The subloading surface can be described based on the expression:

$$
f(\sigma)=R F(H)
$$

where $R$ is the normal yield ratio, $H$ is the isotropic hardening/softening variable and $F$ is the isotropic hardening/softening function, given by

$$
F(H)=F_{0} e^{\left(\frac{H}{\lambda^{*}-k^{*}}\right)} F=F_{0} \exp \left(\frac{H}{\rho-\gamma}\right) ; F^{\prime}=\frac{F}{\rho-\gamma}
$$

where $F_{0}$ is the initial value of $F, \lambda^{*}$ is the slope of the normal consolidation curve and $\kappa^{*}$ is the slope of the swelling curve, both in $\ln v-\ln p$ space ( $v$ is the specific volume and $p \equiv-(\operatorname{tr} \sigma) / 3$ is the mean effective stress). 


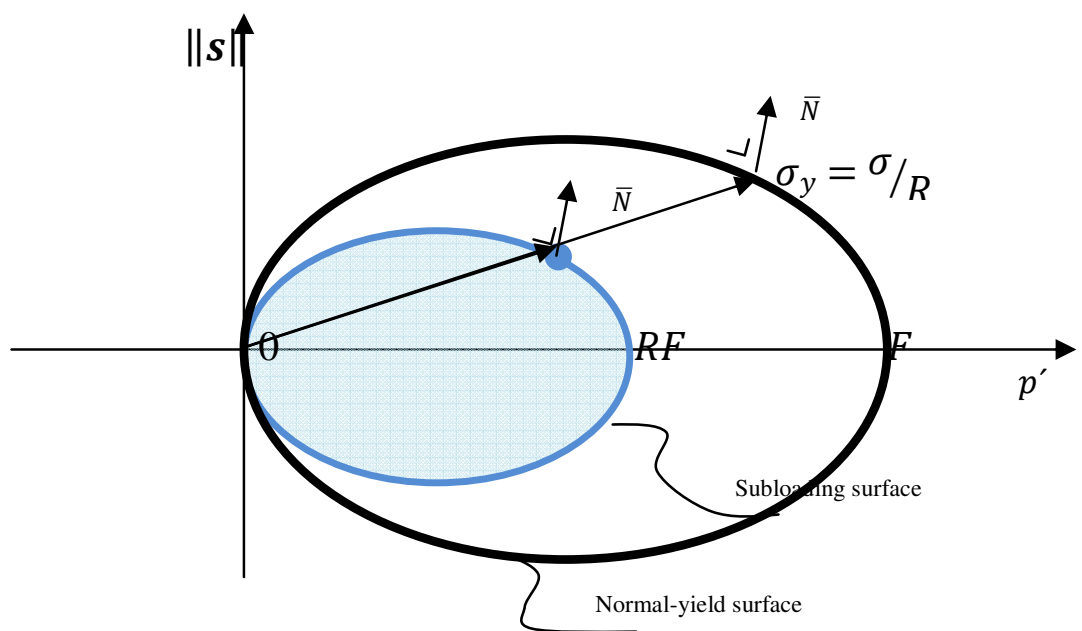

Figure 4 - Normal yield and subloading surfaces.

Expression (2) can assume the same form as the Modified Cam Clay Model [5]:

$$
f(\sigma)=p\left(1+\chi^{2}\right)=R F(H)
$$

where

$$
\chi=\frac{\|\eta\|}{\mathrm{m}}
$$

and

$$
\eta=\frac{s}{p}
$$

The normal to the yield surface $(\overline{\mathrm{N}})$ is given by:

$$
\bar{N}=\frac{1}{\sqrt{\frac{1}{3}\left(1-\chi^{2}\right)^{2}+\left(\frac{2 \chi}{m}\right)^{2}}}-\left[\frac{1}{3}\left(1-\chi^{2}\right) I+\frac{2}{m^{2}} \eta\right]
$$

The model requires five material parameters: $\lambda^{*}, k^{*}, v, u$ and $m$. The state value defining the initial size of the yield surface $F_{0}$ must also be specified. The parameters $\lambda^{*}$ and $k^{*}$, are determined so as to fit, respectively, to the slope of the normal compression line and to the line of elastic unloading/reloading obtained under isotropic stress conditions in a bi$\operatorname{logarithmic}$ representation $(\ln v-\ln p)$, unlike the parameters $\lambda, k$ of the Cam Clay Model that are obtained in semi-logarithmic representation $(v-\ln p) . v$ is the Poisson's ratio.

The material constant $u$ is determined so as to adjust the evolution of stiffness with strain in the transition from elastic to elastoplastic behaviour. The lower the value of $u$ the more gradual transition between the two behaviours we have. In the limit, when $u$ tends to infinity, we get the traditional elastoplastic response, with a discontinuity in stiffness.

The constant $m$, which is the slope of the critical state line in the $\left(p^{\prime}, q\right)$ space can be determined from the ratio of the stresses measured at the critical state in the triaxial tests. The constant $m$ is related to the constant $M$ of the Modified Cam Clay model by the expression:

$$
m=\sqrt{\frac{2}{3}} M
$$

The Subloading Surface Model was implemented in the program FLAC to reproduce the same tests for both core and shoulders materials.

Figure 5 and Figure 6 compare, respectively, for the core material and for the shoul- 
ders material, the results obtained in the triaxial tests with those obtained by mathematical modeling using the MCCM and the SSM. The figures show the deviatoric stress invariant versus the axial deformation and the effective stress paths.
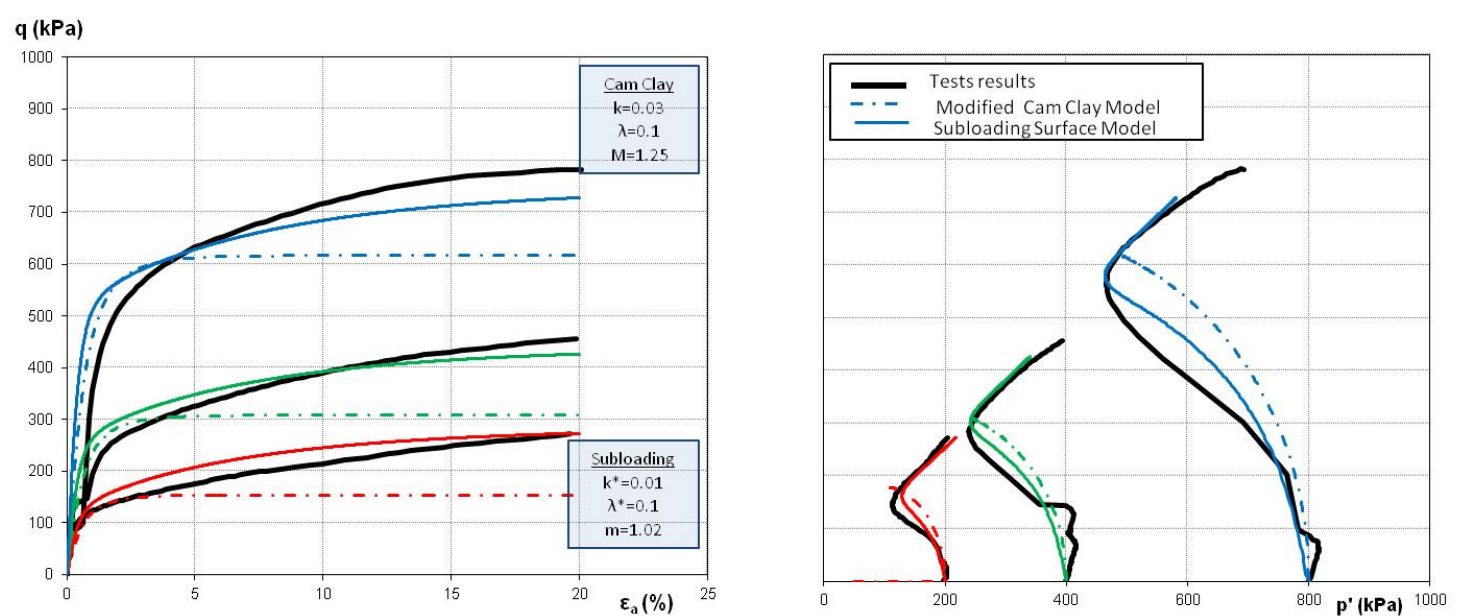

Figure 5 - Comparison between the results of the triaxial tests and the Subloading Surface Model and the Modified Cam Clay Model for the dam's core material.
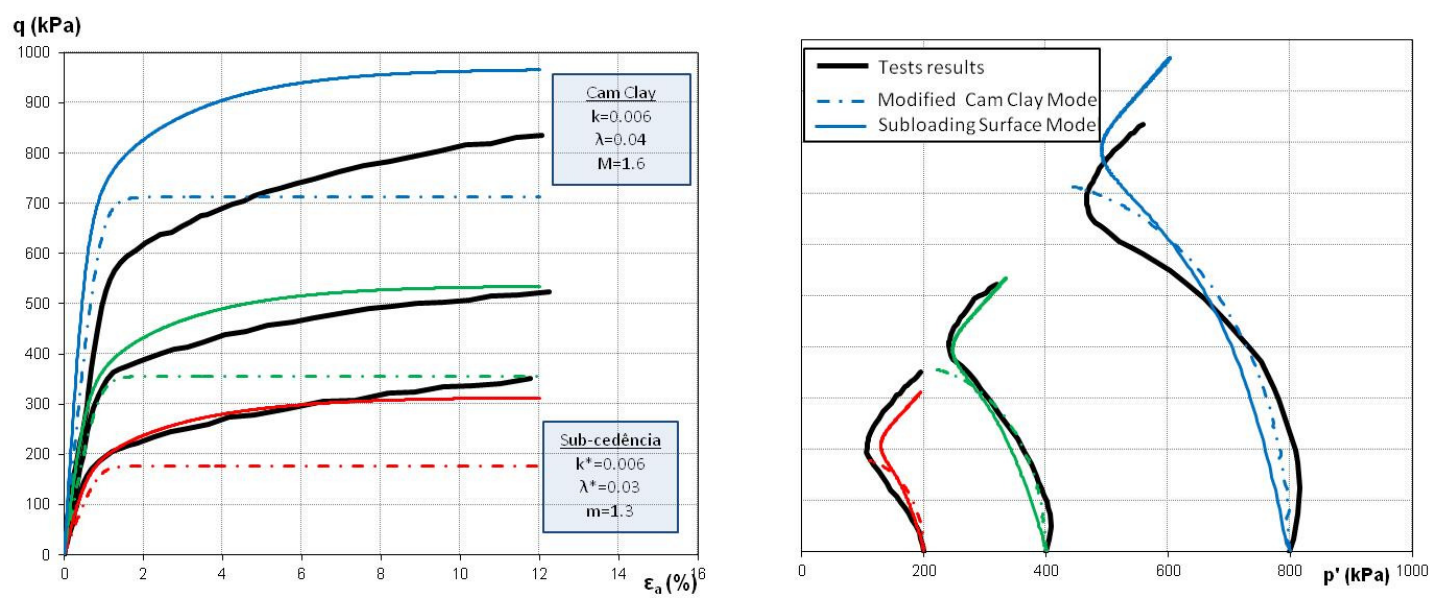

Figure 6 - Comparison between the triaxial test results and both the Subloading Surface Model and the Modified Cam Clay Model for the dam's shoulders material.

The figures show that the Subloading Surface Model is able to reproduce adequately the stress paths, even when a reversal in their direction occurs. It appears that there is a good fit in the case of core materials of the dam (Figure 5). However, this is not the case for the samples of the shoulders (Figure 6). A reasonable fitting is obtained for the samples consolidated at lower isotropic stress values, however, in the case of the sample consolidated at a higher value $(800 \mathrm{kPa})$, the material produces significantly higher deviatoric stresses than the model. There are at least three possibilities as to why this occurs:

1. Variability of the material itself - the material was collected at the same height of the dam and into very close zones, but in the case of a soil and rockfill mixture, it may exhibit some significant variability, as the percentages of different 
dimensions in each sample can be slightly different;

2. The critical state line may not be a straight line with slope constant but a curve whose gradient decreases with the increase of $p^{\prime}$;

3. Initial plastic anisotropy of the material and its evolution with deformation.

\section{ODELOUCA DAM CONSTRUCTION: NUMERICAL ANALYSIS}

\subsection{Geometry discretization and material model constants}

A finite element mesh comprising 5241 elements was used to simulate Odelouca dam construction under plane strain conditions (see Figure 7).

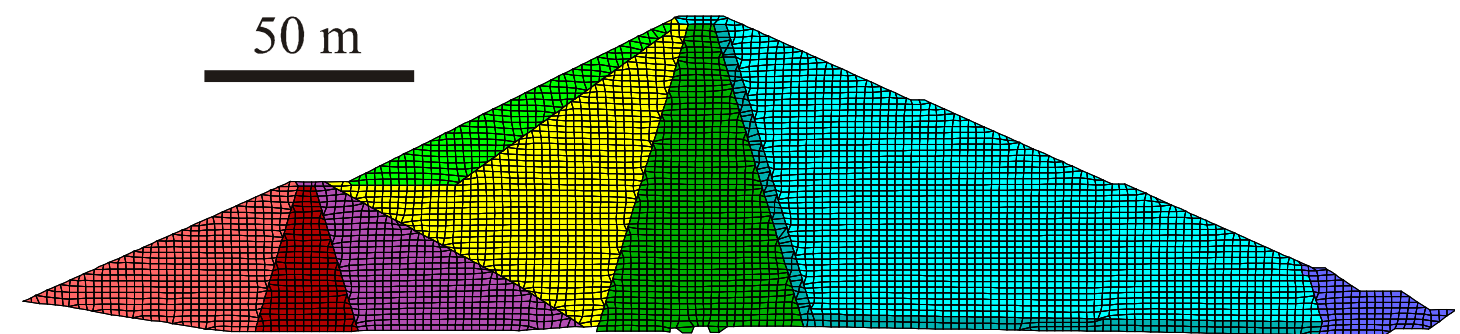

Figure 7 - Odelouca's dam mesh.

This was the first numerical analysis performed using the results obtained from Odelouca Dam. The soil model used was the Modified Cam Cay Model which is a very well know elastoplastic model, widely used in geotechnical analysis.

The analysis presented here is a back analysis in that the results obtained from the monitoring of the construction are already available, but it relies, as much as possible, on the use of material model constants determined from the laboratory tests performed on the materials of the dam.

The material model constants adopted are presented in Table 1. These constants were determined from the laboratory tests carried out during the construction of the dam.

Table 1. Odelouca dam material parameters

\begin{tabular}{ccccccc}
\hline Material & $\lambda$ & $k$ & $M$ & $v$ & $\mathrm{~N}$ & $\begin{array}{c}\rho \\
\left(\mathrm{Mg} / \mathrm{m}^{3}\right)\end{array}$ \\
\hline Core & 0.10 & 0.03 & 1.25 & 0.2 & 1.88 & 2.18 \\
Shoulders & 0.04 & 0.006 & 1.6 & 0.42 & 1.51 & 2.32 \\
Upstream shell & 0.053 & 0.01 & 1.6 & 0.25 & 2.0 & 2.4 \\
rockfill & & & & & & \\
Filter & 0.05 & 0.005 & 1.6 & 0.2 & 1.6 & 1.79 \\
Toe drain rockfill & 0.01 & 0.002 & 2.0 & 0.3 & 2.0 & 2.5 \\
\hline
\end{tabular}


During the analysis, the response in different material regions of the dam can vary between fully drained and undrained, being controlled by the apparent fluid bulk modulus, $K_{f}$. For a fully drained response the value of $K_{f}$ is zero. The effect of the value of $K_{f}$ on the stress path in an undrained triaxial test is illustrated in Figure 8 . The values used the the analysis were $K_{f}=2 \times 10^{4} \mathrm{kPa}$ for the core materials, $K_{f}=2 \times 10^{3} \mathrm{kPa}$ for the shoulders material and $K_{f}=0$ for the other materials.

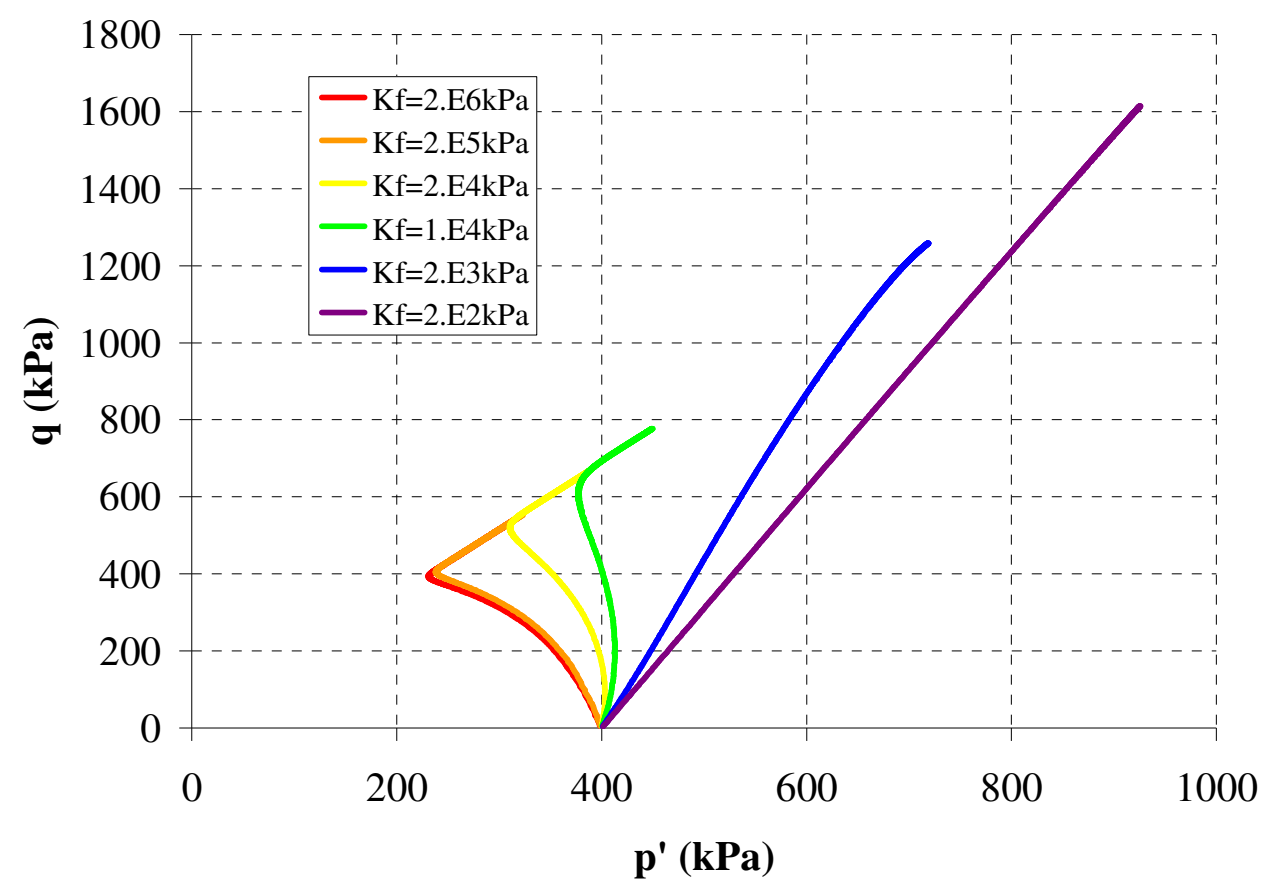

Figure 8 - Influence of the apparent fluid bulk modulus on the undrained effective stress path.

There are two values that must be specified and influence the analysis of the dam construction, incorporating the effect of fill placement conditions (compaction, water content) on the initial state of the material. They are the initial size of the yield surface (due to the compaction energy and matric suction) and the initial effective mean stress (due to matric suction). The latter has no effect in coarse grained materials such as pure rockfill. A value of $400 \mathrm{kPa}$ for the initial size of the yield surface was used for all materials. The value of the initial mean effective stress, in equilibrium with an equivalent negative pore pressure representing the effect of the matric suction (zero total mean stress), used for the shoulders and core materials was $80 \mathrm{kPa}$ and zero for the other materials. Those values were based on the numerical analysis of the laboratory tests.

The construction of the dam is simulated by the sequential activation of elements in 60 horizontal layers, approximately $1.3 \mathrm{~m}$ thick, from the foundation to the crest. In order to be able to compare the computed with the measured settlements, the displacements of the nodes belonging exclusively to the newly placed layer, resulting from the loading stage where the layer is activated, are ignored. The influence of the number of layers on the analysis results was studied, and the settlement values obtained with 10 and 60 layers at the layers' boundaries were very similar (see Figure 9). 


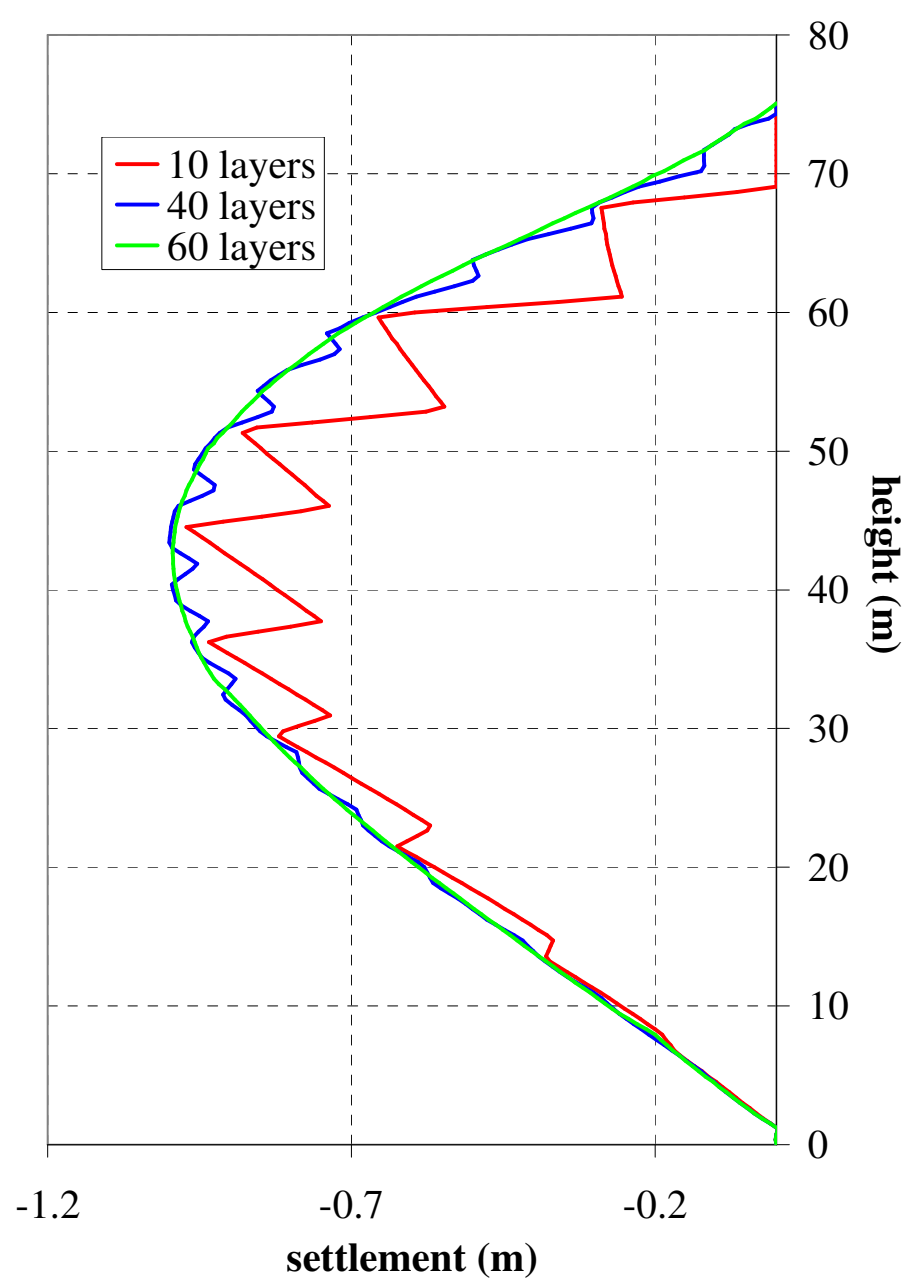

Figure 9 - Computed settlement profile for 10, 40 and 60 layers.

\subsection{Results of the analysis}

In Figure 10 and Figure 11 present, respectively, the vertical stress at elevation $19 \mathrm{~m}$ (from the foundation) and the total vertical stress field of the tallest cross-section of Odelouca dam.

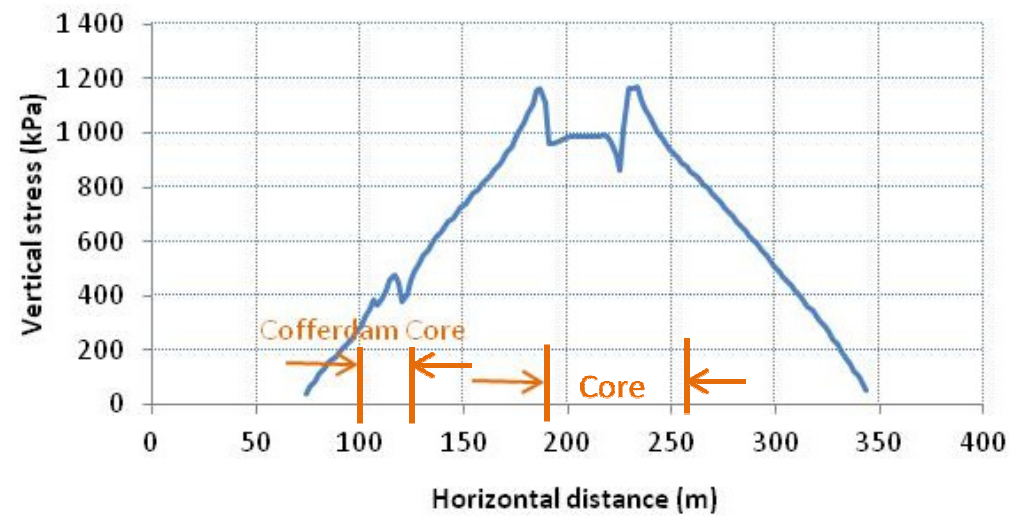

Figure 10 -Total vertical stress at elevation $19 \mathrm{~m}$. 
The figures show that there is a significant stress transfer from the core to the shoulders, resulting in lower stresses in the core and higher stresses in the shoulders.

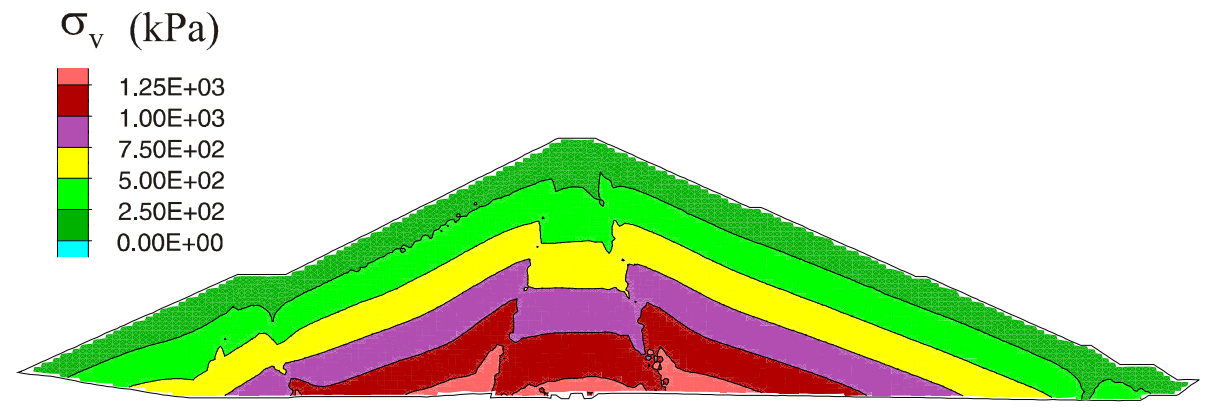

Figure 11 - Total vertical stress field in the tallest Odelouca dam cross-section.

In Figure 12 it is possible to see the measured and computed settlement profiles along a vertical line crossing the crest on the tallest cross-section of Odelouca dam. Figure 13 represents the settlement field at the same cross-section. The higher settlement is about $1 \mathrm{~m}$ (approximately $1.3 \%$ of the dam height) and occurs near the elevation between 40 and $50 \mathrm{~m}$ in the core of the dam.

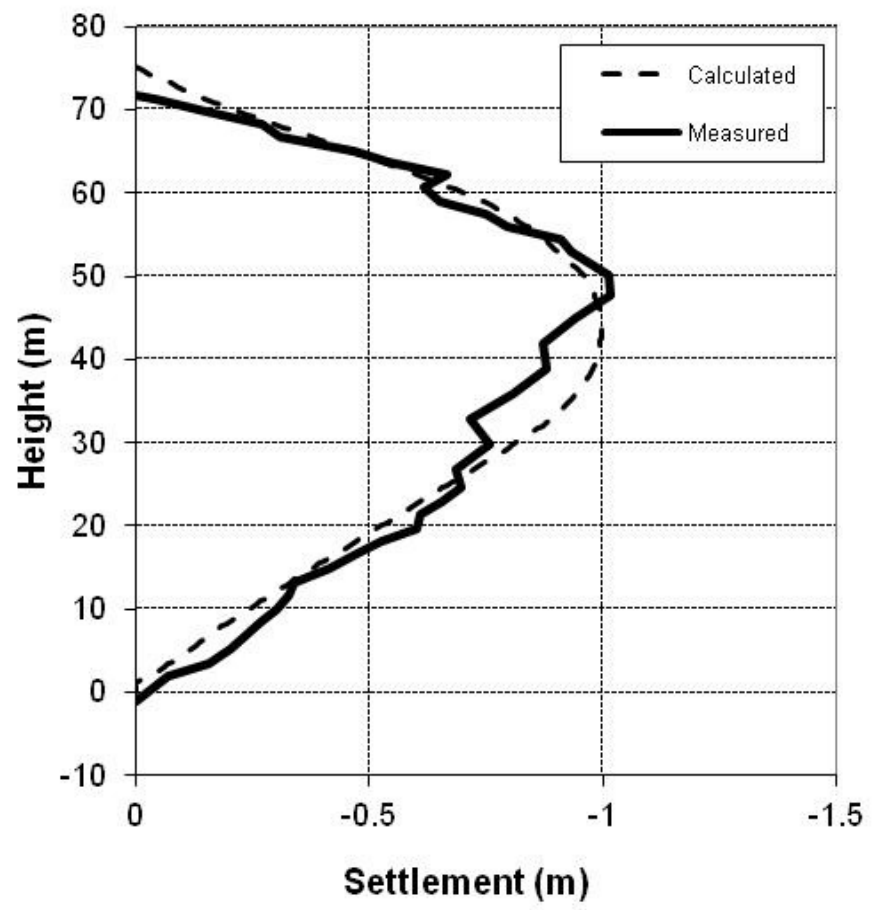

Figure 12 - Settlement profile along a vertical line on the tallest cross section of Odelouca's dam. 


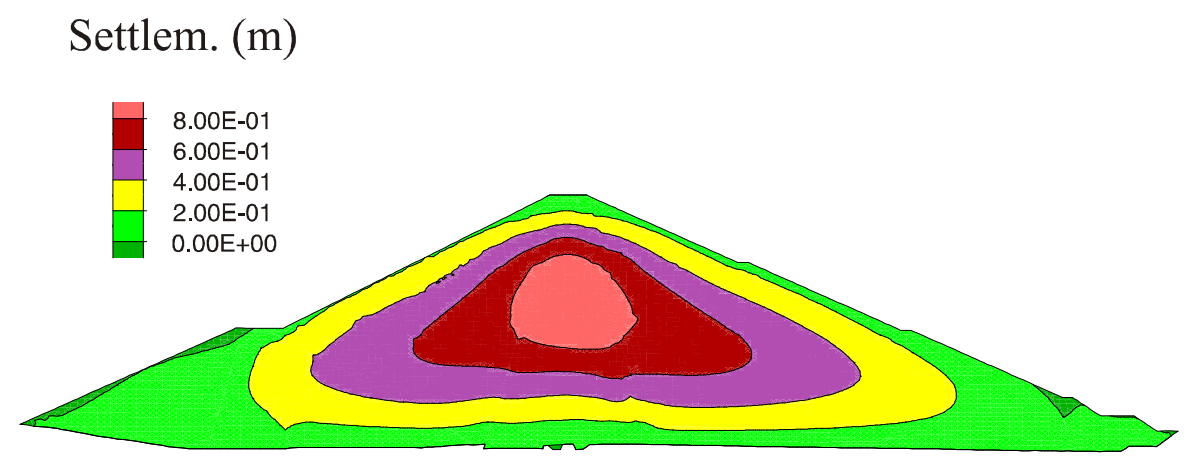

Figure 13 - Settlements in the tallest Odelouca dam cross-section.

In addition, Figure 14 shows the displacements magnified 10 times for the tallest cross-section.

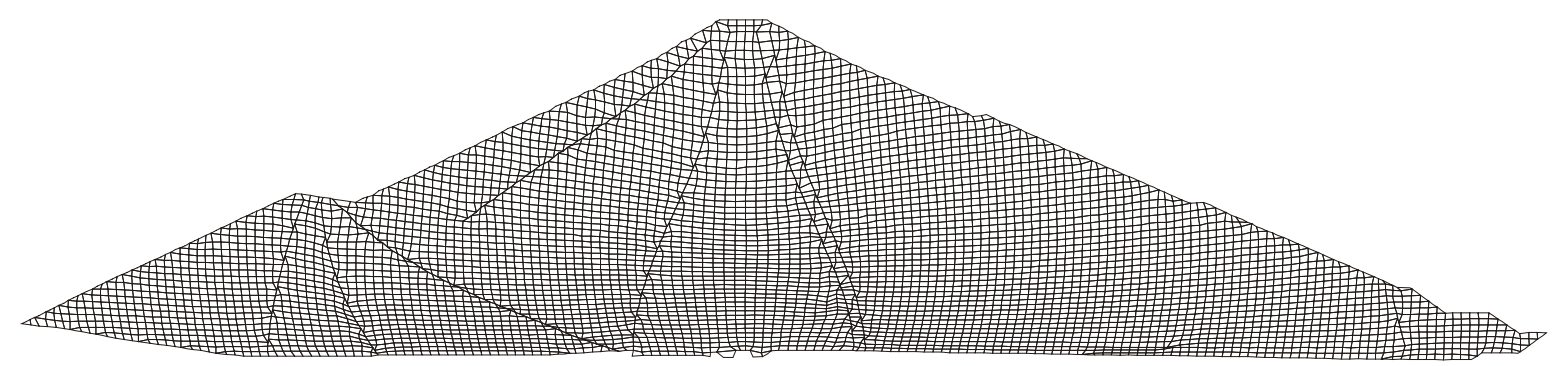

Figure 14 - Deformed mesh (displacements magnified 10 times) in the tallest Odelouca dam cross-section.

In conclusion, Figure 15 shows the total stresses measured in an array of 4 total stress cells located in the upstream shoulder at elevation $19 \mathrm{~m}$ (from the foundation). The results for the horizontal and vertical stresses are very similar to the ones obtained from the numeric analysis. In the case of the shear stress there is only qualitative agreement.
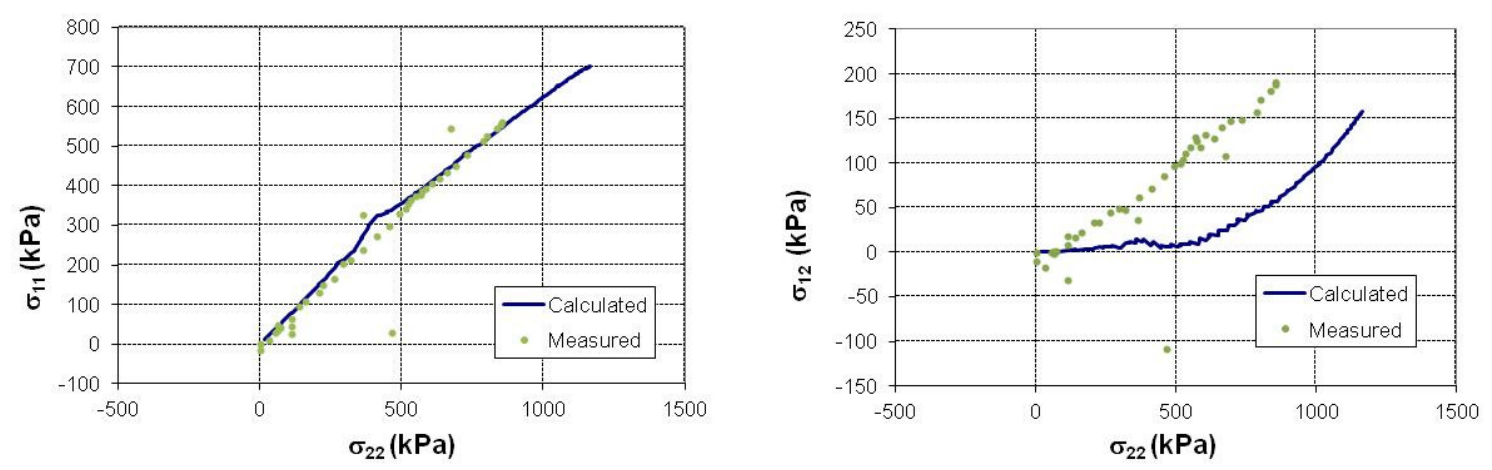

Figure 15 - Total stresses measured in a 4 cell array located in upstream shoulder of the dam at elevation $19 \mathrm{~m}$. 
The results obtained with the numerical analysis of Odelouca dam using the critical state model (Modified Cam Clay Model) presented good adjustments with the measurements made with some of the observation equipment installed in the dam. However, as can be seen in Figure 2, Figure 3, Figure 5 and Figure 6, the MCCM did not fit well the undrained triaxial tests on the core and shoulders materials, especially when there is an inversion in the direction of the effective stress path.

\section{CONCLUSIONS}

In this paper the results of a numeric analysis of Odelouca dam's construction is presented together with the numerical modelling of some of the undrained triaxial tests performed on the core and shoulder materials. These analyses used the explicit finite difference program FLAC.

Results were compared between the Modified Cam Clay Model (existing in the software) with those obtained with a non-conventional elastoplastic model, the Subloading Model, which predicts a gradual transition between the elastic to elastoplastic behaviour, for both materials placed in the dam.

The results obtained from the numerical analysis of Odelouca dam's construction using only the Modified Cam Clay Model are in good agreement with some of the measurements obtained with the observation equipment installed. However, this model was not able to reproduce well the laboratory test results from the core and shoulders materials, especially when there is an inversion in the direction of the effective stress path.

Future developments include the use of more sophisticated models such as the Subloading Surface Model, which was able to reproduce quite well the undrained triaxial tests, in the numerical modelling of the dam construction. There is also the intention of improving the method to determine the initial size of the yield surface and the initial effective stress from the matric suction using the water retention curve of the material together with the knowledge of the water content. Another objective concerns the verification of the capability of the model to reproduce tests performed under different stress paths such as isotropic consolidation and uniaxial strain tests. Also, a more realistic analysis of the dam using a nonsaturated mechanical-flow coupled approach and a model for non-saturated soils is planned. 


\section{Acknowledgements}

The authors would like to thanks the owner of Odelouca dam, Águas do Algarve, SA, for the availability of materials to the tests. We would like also to express gratitude to the LNEC technicians for their contribution to the experimental work.

\section{REFERENCES}

[1] A. Schofielld and P. Wroth, Critical State Soil Mechanics. McGraw-Hill. Londres., 1968.

[2] K. Hashiguchi and M. Ueno, "Elastoplastic constitutive laws of granular materials. Constitutive Equations of Soils," in Proc. 9th Int. Conf. Soil Mech. Found. Engng, Special Session 9, Tokyo, 1977.

[3] K. Hashiguchi, "Constitutive equations of elastoplastic materials with elastic-plastic transition.," J.Appl. Mech. ASME 47, No.2, ., pp. 266-272, 1980.

[4] K. Hashiguchi, " Subloading surface model in unconventional plasticity," Int. J. Solids Struct. 25. No.8, pp. 917-945, 1989.

[5] K. Roscoe and J. B. Burland, "On the generalized stress strain behaviour of wet clay.," in In Engineering Plasticity, eds, Cambridge, England: Cambridge University Press., J.Heyman and F.A. Leckie, 1968, pp. 535-609. 